\title{
COMPOSIÇÃO gUÍMICA E VALOR PROTÉICO DO RESÍDUO DE SOJA EM RELAÇÃO AO GRÃO DE SOJA ${ }^{1}$
}

\author{
Maria Sebastiana SILVA ${ }^{2, *}$, Maria Margareth V. NAVES ${ }^{2}$, \\ Rosicler B. de OLIVEIRA², Oneide de S. M. LEITE ${ }^{2}$
}

\begin{abstract}
RESUMO
Este trabalho teve por objetivo avaliar a composição química e o valor protéico do resíduo de soja, subproduto do processo de extração do óleo de soja. Determinou-se a composição centesimal, o valor energético e o perfil de aminoácidos do resíduo e do grão de soja. O valor protéico foi avaliado mediante índices biológicos. Ratos Wistar machos, recém-desmamados $(\mathrm{n}=24)$, distribuídos em quatro grupos, foram alimentados por dez dias com rações contendo $10 \%$ de proteína (resíduo de soja, soja integral, caseína - controle) ou com ração aprotéica. O resíduo apresentou maior conteúdo protéico (47\%) e menor teor energético (334 kcal/100 g) em relação ao grão de soja ( $40 \%$ e $452 \mathrm{kcal} / 100$ g, respectivamente), além de perfil de aminoácidos essenciais com escore de $101 \%$ em relação ao padrão de referência e digestibilidade protéica de $88 \%$. Segundo os índices RNPR (Relative Net Protein Ratio) e PDCAAS (escore de aminoácidos corrigido pela digestibilidade), a qualidade da proteína do resíduo de soja é similar à do grão integral (valores protéicos de $87 \%$ e $85 \%$, respectivamente). O resíduo de soja é fonte de carboidratos, minerais, fibras e proteína de qualidade nutricional adequada, apresentando vantagens em relação à soja integral tais como menor teor energético e maior concentração protéica.

Palavras-chave: soja, composição química, proteína, valor protéico, resíduo de soja.
\end{abstract}

\section{SUMMARY}

CHEMICAL COMPOSITION AND PROTEIN VALUE OF THE SOYBEAN RESIDUE IN RELATION TO THE SOYBEAN GRAIN. The aim of this research is to evaluate the chemical composition and protein value of soybean residue, which is a sub product of soybean oil extraction. The centesimal composition, energy value and amino acid contents were determined from soybean residue and soybean grain. The protein value was estimated by means of biological indexes. Weaning male Wistar rats $(\mathrm{n}=24)$ were divided into four groups that were fed for ten days with $10 \%$ protein diets (soybean residue, soybean grain, casein- control) or a non-protein diet. The soybean residue showed a greater content of protein ( $47 \%$ ) and lower energetic value (334 kcal/100 g) than soybean grain ( $40 \%$ e $452 \mathrm{kcal} / 100$ g, respectively) and it also showed an essential amino acid score of $101 \%$ compared to the reference pattern and protein digestibility of $88 \%$. Protein quality of soybean residue is similar to the protein of soybean grain (protein values of $87 \%$ and $85 \%$, respectively), according to RNPR (Relative Net Protein Ratio) and PDCAAS (Protein Digestibility-Corrected Amino Acid Score) indexes. The soybean residue is a source of carbohydrates, minerals, fibers and adequate protein in nutritional terms and it shows advantages in relation to soybean grain such as lower energetic value and greater protein content.

Keywords: soybean, chemical composition, protein, protein value, soybean residue.

\section{1 - INTRODUÇÃO}

A soja é um produto agrícola de grande interesse mundial graças à versatilidade de aplicação de seus produtos na alimentação humana e animal e ao seu valor econômico nos mercados nacional e internacional. O Brasil figura entre os maiores produtores de soja do mundo, sendo a leguminosa cultivada em várias regiões do País [19].

A relação entre o consumo de soja e a saúde humana tem sido amplamente investigada pelas características nutricionais desse alimento, quer seja o elevado teor de proteína de qualidade nutricional adequada, o conteúdo significativo de minerais e fibras, ou ainda, a quantidade reduzida de gordura saturada e a ausência de colesterol [12, 22, 33]. Mais recentemente, a soja tem sido pesquisada também como fonte de substâncias denominadas fitoquímicos, entre

${ }^{1}$ Recebido para publicação em 13/5/2005. Aceito para publicação em 6/7/2006 (001527)

${ }^{2}$ Faculdade de Nutrição, Universidade Federal de Goiás,

Rua 227, Quadra 68, s/n ${ }^{\circ}$, Setor Leste Universitário, C. P. 131,

CEP 74605-080, Goiânia (GO), Brasil,

E-mail:mssilva@fanut.ufg.br

* A quem a correspondência deve ser enviada os quais os flavonóides, tendo sido observada uma relação entre o consumo de soja e a redução dos riscos de doenças crônicas não-infecciosas como as doenças cardiovasculares, alguns tipos de cânceres e osteoporose [7, 16, 20, 22, 29].

Apesar da alta produtividade e de suas propriedades nutricionais e funcionais, a soja é ainda pouco usada na dieta do brasileiro. As razões para esse baixo consumo são atribuídas ao seu sabor e odor desagradável por causa da presença de diversos compostos orgânicos nas sementes, à indução de flatulência gerada por oligossacarídeos do tipo estaquiose, rafinose e verbascose, e aos seus componentes antinutricionais [22, 25, 30]. Todos esses fatores contribuem para que grande parte da soja seja utilizada na extração de óleos e seus resíduos sejam destinados, especialmente, à alimentação animal.

Entretanto, a soja e seus derivados constituem matérias-primas altamente promissoras para uso na indústria de alimentos, sobretudo em produtos à base de cereais $\mathrm{e}$ de carnes [2, 6, 18, 31]. A adição apropriada de derivados de soja resulta em produtos alimentícios menos calóricos; com teor de lipídios reduzido e com elevado conteúdo de proteína adequada às necessidades nutricionais de indivíduos 
adultos; mais baratos; além de preservar as características físicas e sensoriais do produto tradicional [6, 18].

Considerando a vasta produção de soja em nosso meio, assim como suas características nutricionais e seu potencial tecnológico, o presente trabalho teve por objetivo avaliar as características químicas e o valor protéico do resíduo de soja, que constitui um subproduto da extração do óleo dos grãos da leguminosa.

\section{2 - MATERIAL E MÉTODOS}

\section{1 - Ingredientes e rações}

O resíduo de soja, obtido a partir da extração do óleo de grãos de soja (Glycine max), foi doado pela Cooperativa Mista dos Produtores Rurais do Sudoeste Goiano Ltda. (Comigo), na forma de farinha. Os grãos de soja integral, obtidos no comércio local de Goiânia, foram macerados por 12 h, cozidos em panela de pressão de uso doméstico durante $20 \mathrm{~min}$, desidratados em estufa com circulação forçada de ar (Fanem, $315 \mathrm{SE}$ ) por $48 \mathrm{~h}$ a $50{ }^{\circ} \mathrm{C}$. Em seguida, foram triturados em moinho (Tecnal, tipo Willy - TE - 650), obtendo-se a farinha. Além desses, foram usados os seguintes ingredientes nas rações: mistura de vitaminas (Roche, São Paulo); e caseína e mistura de minerais (Rhoster, São Paulo).

Foram preparadas quatro rações, sendo duas rações experimentais (resíduo de soja e grão integral), uma raçãocontrole (caseína) e uma aprotéica (sem adição de proteína). As rações foram elaboradas de acordo com a composição básica preconizada para ensaio com rato, descrita no método 960.48 da Association of Official Analytical Chemists [3], contendo $10 \%$ de proteína (exceto a aprotéica), $8 \%$ de óleo, $5 \%$ de mistura mineral, $1 \%$ de mistura vitamínica, $1 \%$ de celulose microcristalina (adicionada às rações controle e aprotéica) e amido de milho em quantidade suficiente para atingir $100 \%$.

\section{2 - Análises químicas}

Os ingredientes (resíduo de soja, grão integral e caseína) foram analisados quanto aos teores de umidade, lipídios totais (extrato etéreo), fibra bruta e resíduo mineral fixo (cinzas), conforme técnicas descritas pelo INSTITUTO ADOLFO LUTZ [13]. Analisou-se o nitrogênio total, segundo o método semimicro de KJELDAHL [3], que foi transformado em proteína bruta usando os fatores de conversão respectivos para cada fonte protéica [8]. Os carboidratos foram estimados por diferença. O valor energético total das fontes protéicas foi calculado considerando-se os fatores de $4 \mathrm{kcal}$ por grama de proteínas e de carboidratos, e de $9 \mathrm{kcal}$ por grama de lipídios. Os dados da composição centesimal das fontes protéicas das rações usadas no ensaio biológico estão apresentados na Tabela 1.

A análise da composição em aminoácidos essenciais da proteína do resíduo e do grão de soja foi realizada no Centro de Química de Proteínas da Faculdade de Medicina de Ribeirão Preto da USP. A determinação dos aminoácidos, exceto o triptofano, foi feita após hidrólise da proteína em solução ácida, em analisador de aminoácidos (Nicolas V, Ribeirão Preto) e detecção colorimétrica pós-coluna com ninidrina [1, 27]. O triptofano foi determinado, após hidrólise alcalina, mediante técnica colorimétrica, conforme descrito por SPIES [28]. A partir dos dados destas análises, foi estimado o escore de aminoácidos essenciais (EAE), usando-se como referência as necessidades de aminoácidos essenciais de crianças em idade pré-escolar [9]. Calculou-se também o valor protéico dos produtos de soja por meio do índice PDCAAS (Protein Digestibility-Corrected Amino Acid Score), que corresponde ao produto do EAE pela digestibilidade verdadeira da proteína [9].

\section{3 - Ensaio biológico}

Foram utilizados 24 ratos albinos, machos, da linhagem Wistar, recém-desmamados, com pesos entre 48 e 62 g (média $=55,8 \pm 4,1 \mathrm{~g}$ ), gerados no Laboratório de Nutrição Experimental da Faculdade de Nutrição da UFG a partir de matrizes SPF (Specific Patogen Free), provenientes do Centro de Bioterismo da Universidade Estadual de Campinas - Unicamp (Campinas-SP). Os animais foram distribuídos nos grupos conforme delineamento por blocos casualizados, contendo quatro tratamentos e seis repetições. Os ratos foram mantidos em gaiolas individuais por doze dias, sendo os dois primeiros dias de adaptação e dez dias de experimento, em ambiente com temperatura entre $20^{\circ} \mathrm{C}$ e $25^{\circ} \mathrm{C}$, umidade variando de $40 \%$ a $70 \%$ e ciclos claro-escuro de doze horas. As rações e água filtrada foram oferecidas ad libitum. O consumo de ração foi monitorado, assim como o peso dos animais, que foi aferido em balança eletrônica digital nos dias $0,4,7$ e 10 do experimento. Durante os últimos três dias do experimento, foram colhidas as fezes dos animais para análise do seu teor protéico.

A qualidade nutricional das rações foi avaliada por meio de diferentes índices biológicos. Foi calculado o fator de conversão alimentar (FCA) que corresponde à relação entre a ração consumida e o ganho de peso dos animais [23]. Para se avaliar a qualidade protéica foi determinado o índice NPR (Net Protein Ratio) [24], sendo NPR = ganho de peso do grupo teste $(\mathrm{g})+$ perda de peso do grupo aprotéico (g)/proteína ingerida do grupo teste (g). O NPR relativo (RNPR)

TABELA 1 - Composição centesimal aproximada (g/100 g) e valor energético (kcal/100 g) das fontes protéicas das rações usadas no ensaio biológico ${ }^{(1)}$

\begin{tabular}{lclcrrrr}
\hline Fonte protéica & Umidade & Energia & Proteínas & Lipídios & Carboidratos & Fibras & Cinzas \\
\hline Caseína & 7,75 & 351,5 & 81,5 & 0,67 & 4,87 & 0,13 & 5,08 \\
Soja (grão) & 5,60 & 451,6 & 40,4 & 24,55 & 17,26 & 9,31 & 2,88 \\
Soja (resíduo) & 8,40 & 334,1 & 46,7 & 1,67 & 33,10 & 4,97 & 5,20 \\
\hline
\end{tabular}

(1) Os dados constituem médias de três repetições. 
foi estimado usando-se como referência o valor de NPR do grupo controle. A partir dos valores de NPR, calculou-se o índice NPU (Net Protein Utilization = 3,3 + 15,5 NPR) [4]. Foi determinado, ainda, para o cálculo do índice PDCAAS, a digestibilidade verdadeira da proteína (Dv) que expressa a proporção da proteína ingerida que é absorvida, conforme preconizado para ensaios in vivo [9].

A análise estatística dos dados do ensaio biológico foi feita por meio de análise de variância (Anova) e do teste de Tukey a $5 \%$ de probabilidade, exceto para o caso do valor protéico, em que se utilizou o teste $t$ de Student.

\section{3 - RESULTADOS E DISCUSSÃO}

Os dados da composição centesimal e do valor energético (Tabela 1) indicaram que o resíduo de soja contém maior conteúdo de proteínas, carboidratos e cinzas, e menor quantidade de energia, lipídios e fibras em relação ao grão. O menor valor energético e o baixo teor de lipídios eram esperados, visto que o resíduo de soja foi obtido por meio da extração do óleo dos grãos de soja. Neste processo, provavelmente, também se removeu parte do resíduo fibroso, o que explica a menor quantidade de fibras em relação ao grão integral. De acordo com os resultados da composição centesimal, o resíduo de soja possui uma boa qualidade química-nutricional, sendo fonte de carboidratos (33\%), proteínas (47\%), minerais (cinzas - 5\%) e fibras (fibra bruta - 5\%).

O conteúdo de proteína do grão de soja (40\% - Tabela 1) se assemelha ao encontrado em variedades dessa leguminosa cultivadas no Brasil (41\%), China e Estados Unidos (42\%) [12]; enquanto que o teor protéico do resíduo de soja apresentou-se similar ao da farinha de soja (46\%) e da proteína texturizada de soja (47\%) [11].

Quanto à composição em aminoácidos essenciais ( $T a-$ bela 2), os valores constatados para o grão e o resíduo de soja são compatíveis com dados de literatura para proteína de soja [8, 11,33], inclusive para cultivares desenvolvidos no Brasil [30]. No caso do triptofano, o valor de $14 \mathrm{mg} / \mathrm{g} \mathrm{de}$ proteína, relatado pela FAO [8] e por GARCÍA et al. [11], encontra-se mais próximo aos evidenciados no presente trabalho. Ressalta-se que tanto o grão quanto o resíduo de soja apresentam perfis de aminoácidos essenciais superiores ao padrão de referência para pré-escolares (Tabela 2), indicando o potencial do resíduo de soja como fonte de proteína de boa qualidade. Os valores de EAE do grão e do resíduo de soja do presente trabalho foram similares ao da proteína de soja (EAE $=97 \%$ ) descrita pela FAO [9] e, conforme o esperado, superiores aos da proteína de feijões [32].

TABELA 2 - Conteúdo e escore de aminoácidos essenciais do grão e do resíduo de soja (mg aminoácidos/g de proteína) em relação ao padrão de referência.

\begin{tabular}{lrcc}
\hline \multicolumn{1}{c}{ Aminoácido } & \multicolumn{2}{c}{ Soja } & $\begin{array}{c}\text { Padrão } \\
\text { FAO/WHO(1) }\end{array}$ \\
\cline { 2 - 3 } & Grão & Resíduo & 19 \\
Histidina & 29,2 & 27,1 & 28 \\
Isoleucina & 53,1 & 47,0 & 66 \\
Leucina & 88,5 & 78,8 & 58 \\
Lisina & 59,6 & 59,8 & 25 \\
Metionina + cistina & 28,7 & 25,2 & 63 \\
Fenilalanina + tirosina & 109,3 & 98,5 & 34 \\
Treonina & 46,3 & 43,6 & 11 \\
Triptofano & 11,2 & 12,2 & 35 \\
Valina & 57,2 & 57,4 & - \\
\hline EAE (\%) & 101,8 & 100,8 & \\
\hline
\end{tabular}

${ }^{(1)}$ Corresponde às necessidades de aminoácidos essenciais de crianças em idade pré-escolar [9]; ${ }^{(2)}$ Escore de aminoácidos essenciais (menor proporção de aminoácido essencial em relação às necessidades do pré-escolar).

Em relação aos resultados do ensaio biológico (Tabela 3), a proteína dos produtos de soja promoveu ganho de peso inferior à caseína (diferenças significativas, $\mathrm{p}<0,05$ ), uma vez que os consumos de ração e de proteína não diferiram entre os grupos de animais ( $>$ > 0,05). Na Figura 1, está apresentada a evolução de peso dos ratos durante o experimento, em que se denota semelhança entre os produtos de soja em promover o crescimento dos ratos.

De acordo com os resultados do fator de conversão alimentar (FCA) (Tabela 3), a ração contendo resíduo de soja foi mais eficaz em promover crescimento que a do grão de soja, e ambas foram inferiores à ração com caseína (diferenças significativas, $\mathrm{p}<0,05$ ). Em estudo que utilizou condições experimentais similares às do presente trabalho [23], a eficácia de conversão alimentar de uma ração contendo arroz e feijão como fontes de proteína foi de 3,54, valor próximo aos constatados para os produtos de soja. Esses dados mostram que a introdução de produtos vegetais reduz a utilização biológica de rações, pois as fontes protéicas de origem vegetal são menos digeríveis que as de origem animal [9, 33].

A qualidade protéica do resíduo é similar à do grão de soja, segundo os índices biológicos NPR e NPU mostrados na Tabela 3. Em relação ao índice NPR, SIKKA et al. [26]

TABELA 3 - Ganho de peso corpóreo, consumo de ração e de proteína e índices biológicos de ratos Wistar mantidos durante dez dias ingerindo rações com diferentes fontes e teores de proteína ${ }^{(1)}$.

\begin{tabular}{|c|c|c|c|c|c|c|}
\hline \multirow[t]{2}{*}{ Grupo/Tratamento } & \multirow[t]{2}{*}{ Ganho de peso (g) } & \multicolumn{2}{|c|}{ Consumo (g) } & \multicolumn{3}{|c|}{ Índice biológico ${ }^{(2)}$} \\
\hline & & Ração & Proteína ${ }^{(3)}$ & FCA & NPR & NPU (\%) \\
\hline Caseína & $45,7 \pm 6,2^{a}$ & $121,5 \pm 11,7^{a}$ & $13,04 \pm 1,26^{a}$ & $2,68 \pm 0,21^{a}$ & $4,04 \pm 0,28^{a}$ & $65,9 \pm 4,4^{a}$ \\
\hline Soja (Grão) & $33,2 \pm 3,5^{b}$ & $120,6 \pm 4,3^{a}$ & $12,30 \pm 0,44^{a}$ & $3,66 \pm 0,32^{b}$ & $3,26 \pm 0,23^{b}$ & $53,9 \pm 3,6^{b}$ \\
\hline Soja (Resíduo) & $37,9 \pm 2,7 \mathrm{~b}$ & $123,6 \pm 7,1^{a}$ & $13,01 \pm 0,74^{a}$ & $3,27 \pm 0,17^{c}$ & $3,45 \pm 0,15^{b}$ & $56,8 \pm 2,4^{b}$ \\
\hline
\end{tabular}

(1) Os dados constituem médias \pm desvios-padrão de seis animais. Em uma mesma coluna, médias com letras iguais não apresentam diferenças significativas a 5 \% de probabilidade pelo teste de Tukey; ${ }^{(2)} \mathrm{FCA}=$ Fator de Conversão Alimentar; $N P R=$ Net Protein Ratio; $N P U=$ Net Protein Utilization; ${ }^{(3)}$ Concentração protéica das rações: caseína (10,73\%); grão de soja (10,20\%); e resíduo de soja (10,53\%). 


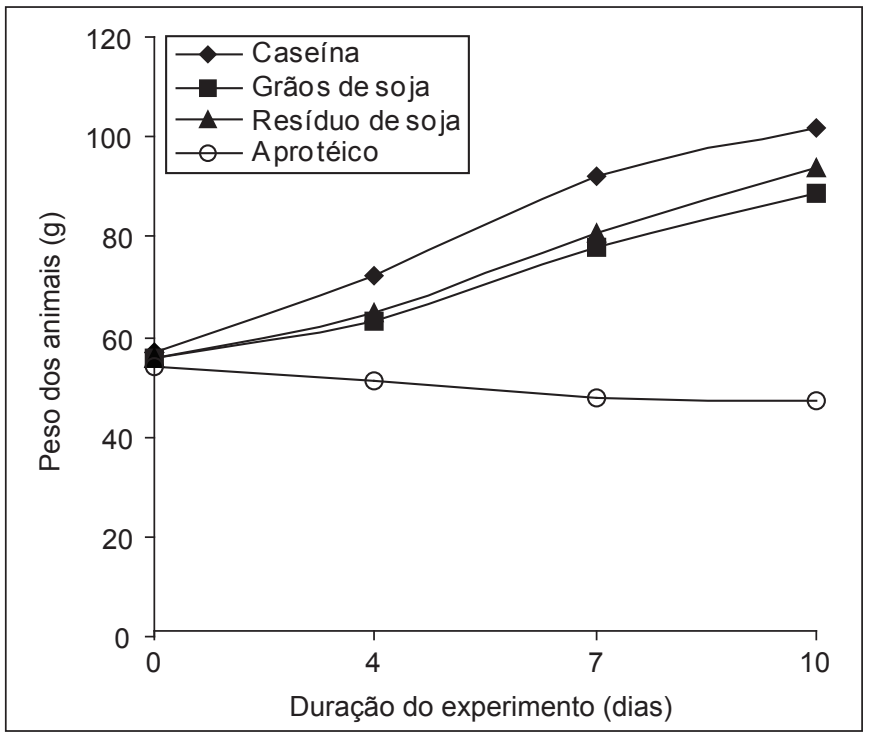

FIGURA 1 - Evolução de peso de ratos Wistar (machos, recémdesmamados) submetidos a diferentes tratamentos durante 10 dias de experimento.

encontraram valores de 2,5 a 3,9 para proteína de grãos de diferentes variedades de soja, e SARWAR [25] relatou o valor 3,7 para proteína isolada de soja.

Conforme os resultados do índice NPU, somente $57 \%$ da proteína do resíduo de soja e $54 \%$ da proteína do grão integral foram biodisponíveis, apesar do perfil de aminoácidos dos produtos de soja atingir $100 \%$ do padrão de referência (Tabela 2). Isto se deve às características do tecido vegetal e da presença de substâncias antinutricionais que limitam a utilização biológica desses alimentos em relação à proteína de origem animal (caseína) [25, 33]. Tais substâncias ou fatores antinutricionais, como, por exemplo, os inibidores de proteases (inibidor de Kunitz), podem inibir a ação das enzimas proteolíticas, quando não são devidamente inativados por ação do calor, limitando assim a digestão protéica com conseqüente redução do ganho de peso e crescimento de animais [5,17]. Os dados de digestibilidade da proteína (Tabela 4) confirmam estas características, uma vez que a proteína dos produtos de soja foi absorvida em menor proporção (média $=87,6 \%$ ) que a caseína $(96,5 \%$ ) (diferenças significativas, $\mathrm{p}<0,05$ ). Esses valores se assemelham aos relatados na literatura, tanto para a proteína de soja quanto para a caseína [9, 21, 25].
O valor protéico dos produtos de soja, em relação ao valor da caseína, está indicado na Tabela 5. Segundo os índices $R N P R$ e PDCAAS, o valor protéico do resíduo é similar ao do grão e ambos apresentam boa qualidade protéica (média $=87 \%$ e $85 \%$, respectivamente). Observa-se que os valores encontrados por meio do índice PDCAAS foram superiores aos do RNPR (diferença significativa para o grão de soja, $\mathrm{p}<$ 0,05). O método PDCAAS foi recomendado como o método mais adequado para avaliar a qualidade protéica de alimentos de origem vegetal [9]. No entanto, nos relatos da literatura denota-se discrepância nos valores desse índice para uma mesma fonte protéica, por causa de diferenças metodológicas, como o padrão de referência para aminoácidos essenciais e a metodologia para determinação da digestibilidade. Por isso, recomenda-se o uso de metodologias in vivo para avaliação da qualidade protéica de produtos vegetais destinados à alimentação humana [14, 33]. Ainda, relata-se que o método PDCAAS pode superestimar a qualidade protéica de alimentos que possuem fatores antinutricionais [25], o que pode explicar os valores de PDCAAS mais elevados que os de RNPR obtidos no presente estudo. Estes resultados podem ser justificados também pelo fato de que métodos biológicos tendem a subestimar a qualidade protéica de leguminosas, pois o modelo experimental comumente usado (rato em fase de crescimento) requer quantidades relativamente maiores de aminoácidos sulfurados em relação aos humanos [10].

Além de ser fonte de proteína de qualidade nutricional adequada, o resíduo de soja é rico em energia (calorias), o que favorece a utilização protéica [10], constituindo-se em mais um fator de interesse a considerar no uso desse produto, sobretudo em situações de consumo insuficiente de alimentos. Por outro lado, o resíduo de soja constitui uma fonte alimentar recomendável em dietas saudáveis que visem à redução dos riscos de doenças crônicas não-infecciosas, especialmente doenças cardiovasculares [7, 15].

O resíduo de soja, subproduto da indústria do óleo de soja, apresenta um grande potencial para ser empregado

TABELA 5 - Valor protéico do grão e do resíduo de soja.

\begin{tabular}{|c|c|c|}
\hline \multirow[t]{2}{*}{ Alimento } & \multicolumn{2}{|c|}{ Valor protéico (\%) } \\
\hline & $R N P R^{(1)}$ & 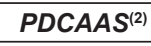 \\
\hline Soja (grão) & $80,7 \pm 5,70$ & $88,6 \pm 0,60^{*}$ \\
\hline Soja (resíduo) & $85,4 \pm 3,81$ & $88,8 \pm 1,46$ \\
\hline
\end{tabular}

TABELA 4 - Consumo de proteína, peso de fezes, proteína excretada e digestibilidade verdadeira (Dv) avaliados em ratos Wistar durante os três dias finais do experimento ${ }^{(1)}$.

\begin{tabular}{|c|c|c|c|c|}
\hline Grupo/Tratamento & Consumo de proteína (g) & Peso de fezes (g) & Proteína excretada $^{(2)}(\mathrm{g})$ & Dv (\%) \\
\hline Caseína & $4,338 \pm 0,583^{a}$ & $1,90 \pm 0,40^{\mathrm{a}}$ & $0,1875 \pm 0,0414^{a}$ & $96,5 \pm 0,6^{a}$ \\
\hline Soja (grão) & $4,384 \pm 0,522^{a}$ & $3,43 \pm 0,35^{b}$ & $0,5837 \pm 0,0646^{b}$ & $87,0 \pm 0,6^{b}$ \\
\hline Soja (resíduo) & $4,621 \pm 0,405^{a}$ & $3,85 \pm 0,45^{b}$ & $0,5802 \pm 0,0824^{b}$ & $88,1 \pm 1,4^{b}$ \\
\hline
\end{tabular}

\footnotetext{
${ }^{11}$ Os dados constituem médias \pm desvios-padrão de seis animais. Em uma mesma coluna, médias com letras iguais não apresentam diferenças significativas a 5 \% de probabilidade
} pelo teste de Tukey; ${ }^{(2)}$ Proteína excretada do grupo aprotéico: 0,0355 $\pm 0,0121$. 
na alimentação humana, particularmente na indústria de alimentos, garantindo assim maior aproveitamento tecnológico do grão de soja e agregação de valor à produção dessa leguminosa. Além disso, o uso do resíduo de soja como matéria-prima de alimentos processados poderia reduzir o custo de produtos destinados à alimentação de grupos específicos da população como crianças, idosos e esportistas, contribuindo para a nutrição adequada e prevenção de doenças carenciais.

\section{4 - CONCLUSÕES}

- O resíduo de soja constitui uma matéria-prima de qualidade nutricional, pois contém aproximadamente $50 \%$ de proteína e teores consideráveis de carboidratos, minerais e fibras, além de menores quantidades de energia e lipídios em relação ao grão integral;

- A proteína do resíduo de soja apresenta um perfil de aminoácidos adequado para suprir as necessidades protéicas de crianças em idade pré-escolar;

- A proteína do resíduo de soja apresenta qualidade nutricional equivalente à proteína do grão da soja; e

- O uso do resíduo de soja é indicado na formulação de alimentos visando o aumento do valor nutricional e possível redução nos custos de produção em relação ao produto tradicional.

\section{5 - REFERÊNCIAS BIBLIOGRÁFICAS}

[1] ALONZO, N.; HIRS, C. H. W. Automation of sample application in amino acid analyzers. Anal. Biochem., v. 23, n. 2, p. 272-288, 1968.

[2] AMAYA-GUERRA, C. A.; ALANIS-GUZMAN, M. G.; SALDÍVAR, S. O. S. Effects of soybean fortification on protein quality of tortilla-based diets produced from regular and quality protein maize. Plant Foods Hum. Nutr., v. 59, n. 2, p. 45-50, 2004.

[3] ASSOCIATION OF OFFICIAL ANALYTICAL CHEMISTS. Official methods of analysis. 16. ed. Arlington: AOAC International, 1995.

[4] BENDER, A. E.; DOELL.; B. H. Biological evaluation of proteins: a new aspect. Br. J. Nutr., v. 11, n.2, p. 140-48, 1957.

[5] CSAKY, I.; FEKETE, S. Soybean: feed quality and safety. Part 1: biologically active components. A review. Acta Vet. Hung., v. 52, n. 3, p. 299-313, 2004.

[6] DHINGRA, S.; JOOD, S. Organoleptic and nutritional evaluation of wheat breads supplemented with soybean and barley flour. Food Chem., v. 77, n. 4, p. 479-488, 2001.

[7] ESTEVES, E. A.; MONTEIRO, J. B. R. Efeitos benéficos das isoflavonas de soja em doenças crônicas. Rev. Nutr., v. 14 , n. 1, p. 43-52, 2001.

[8] FOOD AND AGRICULTURE ORGANIZATION OF THE UNITED NATIONS (FAO). Amino-acid content of foods and biological data on proteins. Rome, 1970. (FAO Nutritional Studies, 24).

[9] FOOD AND AGRICULTURE ORGANIZATION OF THE UNITED NATIONS (FAO). Report of Joint FAO/WHO
Expert Consultation. Protein quality evaluation. Rome, 1991. (FAO Food and Nutrition Paper, 51).

[10] FRIEDMAN, M. Nutritional value of proteins from different food sources. A review. J. Agric. Food Chem., v. 44, n. 1, p. 6-29, 1996.

[11] GARCÍA, M. C; MARINA, M. L.; LABORDA, F.; TORRE, M. Chemical characterization of commercial soybean products. Food Chem., v. 62, n. 3, p. 325-331, 1998.

[12] GRIESHOP, C. M.; FAHEY JR., G. C. Comparison of quality characteristics of soybeans from Brazil, China, and the United States. J. Agric. Food Chem., v. 49, n. 5, p. 2669-2673, 2001.

[13] INSTITUTO ADOLFO LUTZ. Normas analíticas do Instituto Adolfo Lutz. 3. ed. São Paulo, 1985. v. 1.

[14] KANNAN, S.; NIELSEN, S. S.; MASON, A. C. Protein digestibility-corrected amino acid scores for bean and bean-rice infant weaning food products. J. Agric. Food Chem., v. 49, n. 10, p. 5070-5074, 2001.

[15] LAUBER, R.P.; SHEARD, N. F. The American Heart Association dietary guidelines for 2000: a summary report. Nutr. Rev., v. 59, n. 9, p. 298-306, 2001.

[16] LiCHTEnSTEIN, A. H. Soy protein, isoflavones and cardiovascular disease risk. J. Nutr., v. 128, n. 10, p. 1589-1592, 1998.

[17] LIENER, I. E. Implications of antinutritional components in soybean foods. Crit. Rev. Food Sci. Nutr., v. 34, n. 1, p.31-67, 1994.

[18] MCMINDES, M. K. Applications of isolated soy protein in low-fat meat products. Food Tech., v. 45, n. 12 , p. 61-64, 1991 .

[19] MELlO FILHO, O. L.; SEDIYAMA, C. S.; MOREIRA, M. A.; REIS, M. S.; MASSONI, G. A.; PIOVESAN, N. D. Grain yield and seed quality of soybean selected for high protein content. Pesq. Agropec. Bras., v. 39, n. 5, p. 445-450. 2004.

[20] MESSINA, M.; MESSINA, V. Increasing use of soyfoods an their potential role in cancer prevention. J. Am. Diet. Assoc., v. 91, n. 7, p. 836-840, 1991.

[21] MONTEIRO, J. B. R.; COSTA, N. M. B. Avaliação da qualidade protéica de dois formulados em pó, à base de soja enriquecidos com zinco, selênio e magnésio para utilização em nutrição enteral. Ciênc. Tecnol. Aliment., v. 24, n. 1, p. 6-10, 2004.

[22] MORAIS, A. A. C.; SILVA, A. L. Valor nutritivo e funcional da soja. Rev. Bras. Nutr. Clin., v. 15, n. 2, p. 306-315, 2000.

[23] NAVES, M. M. V.; SILVA, M. S.; CERQUEIRA, F. M.; PAES, M. C. D. Avaliação química e biológica do grão em cultivares de milho de alta qualidade protéica. Pesq. Agropec. Trop., v. 34, n. 1, p. 1-8, 2004.

[24] PELLETT, P. L.; V. R. YOUNG. Nutritional evaluation of protein foods. Tokyo: The United Nations University, 1980.

[25] SARWAR, G. The protein digestibility-corrected amino acid score method overestimates quality of proteins containing antinutritional factors and of poorly digestible proteins supplemented with limiting amino acids in rats. J. Nutr., v. 127, n.10, p. 758-764, 1997.

[26] SIKKA, K. C.; GUPTA, A. K.; SINGH, R.; GUPTA, D. P. Comparative nutritive value, amino acid content, 
chemical composition, and digestibility in vitro of vegetable- and grain-type soybeans. J. Agric. Food Chem., v. 26, n. 2, p. 312-316, 1978.

[27] SPACKMAN, D. H.; STEIN, W. H.; MOORE, S. Automatic recording apparatus for use in the chromatography of amino acids. Anal. Chem., v. 30, n. 7, p. 1190-1206, 1958.

[28] SPIES, J. R. Determination of tryptophan in proteins. Anal. Chem., v. 39, n.12, p.1412-1416, 1967.

[29] TAVARES, G. M.; PITANGA, K. C.; SILVA, M. A. T.; MORAIS, A. A. C. A soja como alimento funcional na prevenção do câncer. Rev. Bras. Nutr. Clin., v. 15, n. 2, p. 321-325, 2000.

[30] VASCONCELOS, I. M.; MAIA, A. A. B.; SIEBRA, E. A.; OLIVEIRA, J. T. A.; CARVALHO, A. F. F. U.; MELO, V. M. M.; CARLINI, C. R.; CASTELAR, L. I. M. Nutritional study of two Brasilian soybean (Glycine max) cultivars differing in the contents of antinutritional and toxic proteins. J. Nutr. Biochem., v. 12, n.1, p. 55-62, 2001.
[31] VEGA M., J. A.; FELÍCIO, P. E. Substituição parcial de carne por plasma bovino desidratado e isolado protéico de soja em hambúrguer de frango. Ciênc. Tecnol. Aliment., v. 7, n. 2, p. 123-144, 1987.

[32] WU, W.; WILLIAMS, W. P.; KUNKEL, M. E.; ACTON, J. C.; HUANG, Y.; WARDLAW, F. B.; GRIMES, L. W. True protein digestibility and digestibility-corrected amino acid score of red kidney beans (Phaseolus vulgaris L.). J. Agric. Food Chem., v. 43, n.5, p.1295-1298, 1995.

[33] YOUNG, V. R. Soy protein in relation to human protein and amino acid nutrition. J. Am. Diet. Assoc., v. 91, n. 7, p. 828-835, 1991.

\section{6 - AGRADECIMENTOS}

Ao CNPq e à Cooperativa Mista dos Produtores Rurais do Sudoeste Goiano Ltda.(Comigo)/GO, pelas bolsas de pesquisa concedidas, e à Fundação de Apoio à Pesquisa (Funape) da UFG, pelo apoio financeiro. 